photograph. The title, or a description of the object under examination, may also be obtained on the plate at the same time as the object is photographed. A card on which the title has been written is placed on a slide which is inserted through an opening in the side of the body. The card is illuminated by a lamp within the body and its image projected by a lens on to the photographic plate.

The rack and pinion movement of the usual type of microscope has been replaced by a spiral screw of $1 \mathrm{~mm}$. pitch cut on a cylindrical steel rod. This rod passes through an adjustable hollow pillar which is mounted vertically at one side of the body. The stage and the sub-stage are clamped to this pillar and can be moved up or down by turning the divided head at the top of the rod. Fine adjustment is effected by the rotation of an eccentrically mounted steel disc operating a lever, the short arm of which raises or lowers the pillar carrying the stage.

For the observation of opaque objects the instrument is provided with two horizontal guide bars mounted on the top of the body. These carry a second lamp house and also a condensing system. Vertical illumination is obtained by means of reflectors of the Beck universal type which can be slipped into a mirror holder mounted on the microscope tube in such a manner as to be capable of being moved back wards and forwards, and of being tilted in any direction. Entire control of the illumination is thus obtained.

The instrument described can be used for metallurgical, biological, or petrological work. Simpler types have been designed for use in routine work, where a universal instrument is not required. Geometric bearings have been adopted for all sliding parts so as to secure ease of movement and accuracy of adjustment. The instrument is built throughout on the lines of a precision machine tool. The design obviates the introduction of any delicate part, and the construction is such that the instrument may, if necessary, be put into the hands of an unskilled operator without fear of damage.

\title{
A New Bottom-Sampler for Oceanographical Research.
}

DROF. MARTIN KNUDSEN has published (Meddelelser fra Kommissionen for Havundersøgelser, Serie: Fiskeri, Bind 8, Nr. 3, 1927) an account of a new instrument which he has designed for obtaining samples of the sea bottom, together with the animals living therein. It is specially designed for use on hard bottoms, such as compact sand, where it has been realised that the instrument in most general use, the Petersen grab, is seriously lacking in penetrative power. The new sampler is filled by means of a pump which surmounts it, and the catch is retained by an ingenious 'tipping' device. The pump is operated from on board, being driven by a drum which is made to revolve by the same cable that serves for lowering and hauling the machine. An excellent feature of the sampler is that, when operating properly, it provides a sample which is stratified as in situ.

An accompanying paper ( $\mathrm{Nr} .4$ of the same publication) by Dr. A. C. Johansen gives an account of the preliminary trials of Prof. Knudsen's sampler and furnishes a quantitative comparison of the samples obtained by this method with samples collected at the same time and under the same conditions by means of the Petersen grab. The trials show that the new instrument samples the sea-floor to a depth of $12 \cdot 0-25 \cdot 0 \mathrm{~cm}$., as compared with a penetration of but $0 \cdot 5-3.0 \mathrm{~cm}$. by the Petersen grab. The area sampled is 0.1 square metre, and tables are given comparing the catches with those by two Petersen grabs sampling 0.1 square metre and 0.2 square metre respectively.

The quantitative results of these comparison tests are very striking. The average amount of bottom material per unit area taken by the Knudsen sampler on sandy bottom was found to be more than twenty times that taken by the smaller Petersen grab and more than ten times that taken by the larger. The average weight of animals captured per unit area was about five times that taken by the smaller grab and about four times that by the larger. The alcohol weight of the animals taken in one comparison off Fan $\varnothing$ was for the Knudsen sampler about thirty times that obtained with the smaller grab and more than twenty times that with the larger, whilst the bulk of the species taken were totally unrepresented in the grab hauls, showing conclusively the vital importance of penetrating far enough into the bottom to obtain the burrowing species.

There is, therefore, ample evidence of the success of Prof. Knudsen's bottom sampler and of its importance and value for quantitative investigation of the sea bottom. The sampler is necessarily somewhat complicated and as described would probably be difficult to operate in other than calm and shallow waters. The principles embodied in it, howeverutilisation of pressure to fill the sampler and the 'tipping.' device for retaining the catch-will be of great service to all concerned in the elaboration of methods for investigating marine bottom populations.

\section{Science and Primary Production.}

IN his presidential address to the Australasian Association for the Advancement of Science, at Hobart, on Jan. 16, Mr. R. H. Cambage referred to the great need for the further application of science to primary production. This embraces such fundamental utilities as the production of grain, fruit, butter, wool, and meat, and it is a matter for satisfaction that the Commonwealth and State Governments, as well as private bodies, are showing increased appreciation of the value of science to these problems. A few years ago a thorough knowledge of dairy bacteriology and its application to the production of butter, resulted in increasing the output of first grade butter in New South Wales from 48 to 96 per cent.

When referring to wheat Mr. Cambage said : "It is difficult to find anything among the primary products of Australia which owes more to seience than wheat production. This is a matter of national concern, and it is most comforting to know that the great pioneering work carried out by William James Farrer is not only being continued at Departmental experiment farms and Universities, but with most progressive results. New and better drought and rust-resisting varieties of wheat and other grain are being produced, and experiments are being made for the purpose of breeding rust and flag-smutresisting plants which will also have other good characters."

Reference was made to the action of the pastoralists in arranging for the Australian Pastoral Research Trust to receive a contribution at the rate of two shillings

No. 3041 , VoL. 121] 